\title{
Epstein-Barr Virus Infection and Opisthorchiasis: A Story of Cholangiocarcinoma in the Highly Endemic Area
}

\author{
Viroj Wiwanitkit ${ }^{1, *}$ \\ ${ }^{1}$ Surin Rajabhat University, Surin, Thailand \\ "Corresponding author: Viroj Wiwanitkit, Surin Rajabhat University, Surin, Thailand. E-mail: wviroj@yahoo.com
}

Received 2015 July 25; Revised 2015 August 15; Accepted 2016 January 17.

Keywords: Cancer, Epstein-Barr Virus Infections, Cholangiocarcinoma

\section{Dear Editor,}

Cholangiocarcinoma is an important hepatobiliary cancer. It is considered a deadly cancer. This cancer is very common in Indochina area and there are several deaths due to this cancer every year. This cancer is usually late detected. The patients usually present with severe obstructive jaundice. The advanced cancer is usually seen at first diagnosis and it is usually a non resectable mass. Hence, only palliative care is usually provided to the patients with cholangiocarcinoma.

The main endemic countries of cholangiocarcinoma are Laos People's Democratic Republic and Thailand (1). Hundreds of new cases of cholangiocarcinoma are registered in the endemic area (1). The prevention of the cholangiocarcinoma becomes the regional public health policy. It is accepted that chronic opisthorchiasis is the main risk factor of cholangiocarcinoma in this region(1). Of interest, opisthorchiasis is a fluke infestation. The infestation is usually a result of intake of contaminated fresh water fish that is not well cooked. Of interest, raw fish dish is a common local dish in the endemic area, Indochina. In the endemic area, there is a campaign to promote cancer prevention by avoidance of raw fish intake (2). However, there are many additional factors that can promote the cholangiocarcinogenesis including exposure to nitrosamine contamination in local food $(3,4)$ and exposure to contaminated pesticide in local food $(3,4)$. An important possible risk is the concurrent infection. Indeed, there are many tropical infections in the endemic area and some might be considered as risk for promoting cholangiocarcinogenesis. For example, concurrent hepatitis B infection is proved to be a risk $(5,6)$. It is noted that there is a very high rate of hepatitis $B$ seropositive among patients with cholangiocarcinoma ( 5 , $6)$. Indeed, the concurrent viral infection should be specially focused on since many viruses are proved to have the cytopathogenic effect. In fact, the virus infection is proved for induction of carcinogenesis in many cancers such as uterine cervix cancer, nasopharyngeal cancer and hepatocellular cancer. Hence, it is no doubt that the virus infection might have possible role in carcinogenesis of cholangiocarcinoma. Of several viruses, the Epstein-Barr virus should be mentioned. In oncology, Epstein-Barr virus infection is proved for relationship to carcinogenesis of nasopharyngeal cancer. Focusing on cholangiocarcinoma, there are many reports indicating that Epstein-Barr virus infection might cause cellular aberration and this can superimpose the pathology due to chronic opisthorchiasis resulting in increased chance of cholangiocarcinoma development (7). It should be hereby noted that Epstein-Barr virus infection does not directly induce the carcinogenesis of biliary tract but its cytopathogenic effect superimpose the problem $(7,8)$. Focusing on Epstein-Barr virus infection, the seroprevalence of this infection is also extremely high in the Indochinese endemic area of opisthorchiasis and cholangiocarcinoma (9). However, there has never been a study on the possible interrelationship between Epstein-Barr virus infection, opisthorchiasis and cholangiocarcinoma in the Indochinese endemic area. Since the Epstein-Barr virus infection is also a disease that relating to poor hygiene (10), the promotion of hygienic behavior and avoidance of oral contact to others to prevent the concurrent Epstein-Barr virus infection should also be suggested to the local people in in the Indochinese endemic area of cholangiocarcinoma.

\section{References}

1. Kaewpitoon N, Kaewpitoon SJ, Pengsaa P. Opisthorchiasis in Thailand: review and current status. World J Gastroenterol. 2008;14(15):2297-302. [PubMed: 18416453].

2. Sripa B, Pairojkul C. Cholangiocarcinoma: lessons from Thailand. Curr Opin Gastroenterol. 2008;24(3):349-56. doi: 10.1097/MOG.0b013e3282fbf9b3. [PubMed: 18408464].

3. Pairojkul C, Shirai T, Hirohashi S, Thamavit W, Bhudhisawat W, Uttaravicien $\mathrm{T}$, et al. Multistage carcinogenesis of liver-fluke- 
associated cholangiocarcinoma in Thailand. Princess Takamatsu Symp. 1991;22:77-86. [PubMed: 1668894].

4. Wiwanitkit V. Pesticides, fresh water fish, liver flukes and nitrosamines: A story of cholangiocarcinoma development in Thailand. Asian Pac J Cancer Prev. 2009;10(5):961-2. [PubMed: 20162855].

5. Wiwanitkit V. Seroprevalence of hepatitis virus B seropositive in the patients with cholangiocarcinoma: a summary. Asian Pac J Cancer Prev. 2005;6(1):27-8. [PubMed: 15780027].

6. Pinyosophon A, Wiwanitkit V. The prevalence of hepatitis B seropositivity among patients with cholangiocarcinoma. Viral Immunol. 2002;15(4):655-7. doi: 10.1089/088282402320914593. [PubMed: 12516580].

7. Hsu HC, Chen CC, Huang GT, Lee PH. Clonal Epstein-Barr virus associ- ated cholangiocarcinoma with lymphoepithelioma-like component. Hum Pathol. 1996;27(8):848-50. [PubMed: 8760021].

8. Szekely E. Lymphoepithelioma-like cholangiocarcinoma (LELC) not associated with Epstein-Barr virus. Am J Surg Pathol. 2001;25(11):14646. [PubMed: 11684969].

9. Pancharoen C, Mekmullica J, Chinratanapisit S, Bhattarakosol P, Thisyakorn U. Seroprevalence of Epstein-Barr virus antibody among children in various age groups in Bangkok, Thailand. Asian Pac J Allergy Immunol. 2001;19(2):135-7. [PubMed: 11699720].

10. Balfour HJ, Dunmire SK, Hogquist KA. Infectious mononucleosis. Clin Transl Immunology. 2015;4(2):e33. doi: 10.1038/cti.2015.1. [PubMed: 25774295]. 